\title{
Phytochemical investigation, synthesis of gold nanoparticles of Punica granatum and their biological activities against the selected pathogenic microorganism
}

\author{
Fazal U Samad ${ }^{1 *}$, Muhammad Rizwan², Kashif Bashir ${ }^{1}$, Muhammad $^{3}$, \\ Abdur Rauf ${ }^{3}$, Syed Jafer ${ }^{1}$, Bilal Khan ${ }^{1}$, Abdul Malik ${ }^{1}$, Muhammad Anees \\ Ahmad $^{4}$ and Noor U Samad ${ }^{4}$ \\ 1. Department of Microbiology and Biotechnology, Abasyn University Peshawar, Khyber Pakhtunkhwa-Pakistan \\ 2. Center for Biotechnology and Microbiology, University of Swat, Swat-Pakistan \\ 3. Department of Microbiology, University of Swabi, Khyber Pakhtunkhwa-Pakistan \\ 4. Department of clinical medicine (MBBS), Guilin medical University, Guangxi Province-China \\ *Corresponding author's email: fazalsamad12345@gmail.com
}

Citation

Fazal U Samad, Muhammad Rizwan, Kashif Bashir, Muhammad, Abdur Rauf, Syed Jafer, Bilal Khan, Abdul Malik, Muhammad Anees Ahmad and Noor U Samad. Phytochemical investigation, synthesis of gold nanoparticles of Punica granatum and their biological activities against the selected pathogenic microorganism. Pure and Applied Biology. Vol. 10, Issue 4, pp1194-1205. http://dx.doi.org/10.19045/bspab.2021.100126

Received: 02/11/2020 Revised: 22/01/2021

Accepted: 03/02/2021

Online First: 08/02/2021

\section{Abstract}

The current study means to determine the activity of Punica. granatum peel crude extract and gold nanoparticles against pathogenic microorganisms. Five bacterial and three fungal species were used. Fourier-transform infrared spectroscopy (FTIR) and Ultraviolet spectroscopy (UV) of peel extracts and gold nanoparticles (AuNPs) were carried out in a range of 400-4000 nm and 300$700 \mathrm{~nm}$ respectively. Results showed that $P$. granatum peel crude extract have medicinally important phytochemical constituents which have commercial importance to prepare drugs. Synthesized AuNPs were confirmed and characterized by FTIR and (UV-Vis) spectroscopy. Surface plasma resonance (SPR) peak in absorption spectra showed absorption at $525 \mathrm{~nm}$ by using (UV-Vis) spectroscopy. Bioactive compounds from the peel of $P$. granatum and extract mediated AuNPs can be significantly used as an alternate medicine to replace the available antibiotics, which have adverse side effect. $P$. granatum peel were selected instead of other parts because other parts were already screened and have been reported to contain many phytochemical ingredients, making them pharmacologically valuable.

Keywords: Crude extract; FTIR; Gold Nanoparticles; Phytochemical Investigation; Punica Granatum; UV; Pakistan

\section{Introduction}

Punica granatum belongs to the family Punicaceae, and is locally known as Anar. It is present in Srilanka, Iran, Bangladesh,
Pakistan, Afghanistan, California, North Africa and Arizona [1]. P. granatum is associated with a lot of applications regarding health as well as medicinal and 
nutritional features [2]. Punica granatum have a lot of therapeutic uses against arthritis, male infertility, dental condition, and erectile dysfunction [3]. Therapeutic application of the plants is due to the synthesis of various vital chemical, which can be used as medicines. It might rise the idea of manufacturing novel medicines for deadly diseases [4].

$P$. granatum peel is one of the important substance in food/pharmaceutical industry which contain elegiac acid derivative [5]. The peel of $P$. granatum has antimicrobial and antioxidant potential and have higher defensive ability for prostate, colon, lung and skin cancers in addition to use as adjuvant for the cure of breast cancer in humans [6]. Within plant, the therapeutic character is because of existence of some vital compounds, e.g. alkaloids, gums, tannins, volatile oils and glycoside [7]. Phenolic compounds are present in several parts of $P$. granatum e.g. roots, bark, mesocarp, leaves, seeds and exocarp. Estrogenic flavones, ellagitannins flavones, anthocyanin's, anthocynidins flavonoids and punicic acid are the important phytochemicals having industrial uses [8]. P. granatum contain vitamin $\mathrm{C}$ which is crucial nutrient for both animals and human beings. In biological system, it has antioxidant activities and act as cofactor for about eight or more enzymes [9]. Secondary metabolites are present in these plants such as flavonoids, phenolics, alkaloids, volatile oils, steroids and terpenes etc. Various authors have investigated that $P$. granatum plant have medicinal values and extensive variety of activities [10]. Various phytochemical components exist in $P$. granatum plant makes it therapeutically precious [11]. Phytochemical screening of $P$. granatum peel extract give positive results for alkaloids, flavonoids and tannins which showed that $P$. granatum peels extract are biologically active and may be used for the treatment of different diseases [12]. Fractions of gallagic acid, ellagic acid, punicalagins extracted and punicallins from $P$. granatum showed antimicrobial activity when assessed against S. aureus, E. coli, P. aeruginosa, methicillin-resistant and other disease causing bacteria [13].

The ingredients of $P$. granatum showed that crude extract have some significant variations in mineral composition, watersoluble vitamins, sugars, phenolic compounds and organic acids [2].

Bacterial resistant to existing drugs for the treatment of disorders is a serious problem. $S$. aureus is an example showed resistant to most of the antibiotics. In recent times, the adaptation of traditional medicine as an alternative to healthcare and the increases of bacterial resistance to existing drugs have led the authors to investigate the antimicrobial activities of medicinal plants. Different families of the plants have been screened in search of antibacterial agents. These works revealed the potential of many herbs as drug sources $[14,15]$.

Nanotechnology term was first used by Professor Noria Taniguchi of Science University Tokyo in 1974 in order to describe materials at nanometer level. Nanoparticles (NPs) are small particles whose surface layer consist of organic and inorganic molecules and ions. The chemical method for the synthesis of NPs are hazardous which may affect the environment as well as human health. Similarly shelf life of these metallic NPs are very limited. Therefore due to Eco friendliness, high reproducibility and low cost, biological methods are used for synthesis of NPs [16-18].

The present study focused on detection of active phytochemical constituents of $P$. granatum, e.g. by using peel crude extract against different pathogenic microorganism. Further, efficacy of synthesized NPs will be determined. 


\section{Materials and Methods}

Punica granatum peel were collected from local bazaar at Peshawar, Pakistan. The fruit peel were washed shade dried and make powdered for further activities [14].

Preparation of aqueous and methanolic extract

The powder was soaked in distilled water and methanol for about seven days and filtered. By using rotary evaporator the liquid was evaporated at $45-50^{\circ} \mathrm{C}$ [19].

\section{Preparation of fractions}

Extract was dissolved in $100 \mathrm{ml}$ distilled water followed by addition of $200 \mathrm{ml}$ ethyl acetate in separating funnel. The funnel was shaken continuously and then kept for the formation of two layers and separated. Through water bath ethyl acetate was evaporated and fraction was obtained. The same procedures were performed for butanol and chloroform fractions [20].

\section{Phytochemical screening}

$1 \mathrm{mg} / \mathrm{mL}$ concentration was used for phytochemical screening of peel extract according to techniques described by [19, 21].

\section{Test for steroids}

$P$. granatum peel extract $(1 \mathrm{ml})$ was added to $1 \mathrm{ml}$ sulphuric acid and $2 \mathrm{ml}$ chloroform. Reddish brown ring appearance at interface indicate the existing of steroids.

\section{Test for glycosides}

Ammonium solution (10\%) was mixed with $3 \mathrm{ml}$ chloroform and $1 \mathrm{~mL}$ Punica. granatum peel extract. Change of solution to pink color indicates the existing of Glycosides.

\section{Test for saponins}

$5 \mathrm{ml}$ peel extract added to $5 \mathrm{ml}$ of distilled water and shaked in progressed chamber for about fifteen minutes. Development of steady foam showed the presence of saponins.

\section{Test for alkaloids}

$2 \mathrm{ml}$ of concentrated $\mathrm{HCl}$ added to $1 \mathrm{ml}$ of $P$. granatum peel extract and added few drops of Mayer's reagent. White or Green color appearance indicate the existing of alkaloids.

\section{Flavonoids test}

Sodium hydroxide mixed with test solution which increased the yellow coloration followed by addition of few drops of $\mathrm{HCl}$ changed it to colorless, which indicate flavonoids presence.

\section{Test for tannins}

$1 \mathrm{~mL}$ of $P$. granatum peel extract added to $5 \%$ Ferric chloride. Dark blue or greenish black color appearance of the solution indicates the existing of tannins.

\section{Test for quinones}

$1 \mathrm{ml}$ of $P$. granatum peel extract added to $1 \mathrm{ml}$ of concentrated sulphuric acid. Appearance of red color indicate quinones presence.

\section{Preparation of nanoparticles}

20 grams of $P$. granatum peel powdered was added to $250 \mathrm{ml}$ Erlenmeyer flask along with $100 \mathrm{ml}$ of distilled water. The flask was heated for 10 minutes then filtered with Whatmann filter paper. $50 \mathrm{ml}$ solution $(1 \mathrm{mM})$ of gold salt and $5 \mathrm{ml}$ of peel filtered extract solution was mixed and kept at room temperature with intermittent shaking. The dark ruby pink red appearance of the solution indicate the formation of AuNPs. The solution was centrifuged for 15 minutes in order to separate NPs from the solution. Made powdered for further activities [22].

\section{Fourier transform infrared spectroscopy}

The FTIR analysis was carried out in Materials Research Laboratory (MRL) Department of Physics, University of Peshawar, Pakistan, in order to characterize the crude extract and AuNPs according to technique described by [23].

\section{Ultra violet visible spectrophotometer}

By means of ultra violet visible spectrophotometry, gold nanoparticles were detected by the protocol of [23] at (MRL) Peshawar in a range of 300-700 nm.

\section{Test microorganisms}

Clinical isolates of $E$. coli, S. typhi, $K$. pneumonia, $S$. aureus and $P$. aeruginosa 
were used for antibacterial activity and Rhizopus, Aspergillus bronchitis and Aspergillus terreus were used for antifungal activity, which provided by Pakistan Council of Scientific and Industrial Research (PCSIR) Peshawar.

\section{Screening for antibacterial potential}

Muller Hinton agar (MHA), was prepared by standard operating procedures and autoclaved for 15 minutes at $121^{\circ} \mathrm{C}$. Then the media was poured in to sterile petri plates and kept for solidification. Sterilized swab was used in order to prepare a homogenous lawn. Uniform lawn of each test species was prepared by spreading on the entire surface of the plates. 3 wells of $8 \mathrm{~mm}$ diameter and 5 mm depth by using sterile borer. 50, 75 and $100 \mathrm{ml}$ of plant extract was applied to each well. Same procedure was used against fungal species by using potato dextrose agar (PDA) instead of nutrient agar. Gentamicin was used as positive control and Dimethyl Sulfa Oxide (DMSO) was used as negative control for bacterial species. All the plates were incubated at $37^{\circ} \mathrm{C}$ for 24 hours. Measured zone of inhibitions after incubation period in $\mathrm{mm}$ according to technique described by [15].

\section{Free radical scavenging activity}

Through DPPH (1, 1-diphenyl-2picrylhydrazyl) free radical assay the percentage of antioxidant activity of crude extract was measured by the technique as described by [24]. 1mM solution of DPPH and secondly extract standard solution in $1 \mathrm{mg} / \mathrm{ml}$ was prepared. From extract stock solution $1.5,2.5$ up to $9.50 \mathrm{ml}$ was taken. To these standard solutions $8.5,7.5$ up to $0.5 \mathrm{ml}$ of pure methanol was added in order to prepare $(150,250$ up to $950 \mu \mathrm{g})$ solution. One $\mathrm{ml}$ of $1 \mathrm{mM}$ solution of DPPH was added to every test tube and kept for 30 minutes at $25^{\circ} \mathrm{C}$. UV readings was taken after 30 minutes at $517 \mathrm{~nm}$. Calculate absorbance by following formula.

$\%$ Inhibition $=\frac{A c-A s}{A c} \times 100$
Where;-

$A_{c}=$ Absorbance of control

$\mathrm{A}_{\mathrm{s}}=$ Absorbance of sample

\section{Results}

Present research work means to determine the antibacterial, antifungal and antioxidant activity of Punica granatum peel extract and nanoparticles. E. coli, S. typhi, P. aeruginosa, $K$. pneumonia, and $S$. aureus of bacterial species and Rhizopus, Aspergillus terreus and Aspergillus bronchitis of fungal species were used. Standard operating procedure was used to perform these activities.

\section{Fourier transform infrared spectroscopy} results

Fourier Transform Infrared Spectroscopy of $P$. granatum peel extract was carried out it range of 400-4000 nm. Different peaks were detected each peak indicate the presence of chemical compounds like carboxylic acid, Phenol, alkene, alkyl halides etc as shown in (Fig. 1).

\section{FTIR of plant mediated AuNPs}

FTIR analysis was carried out in order to find out AuNPs associated biomolecules. Different peaks of active compounds were detected which indicate the presence of chemical compounds as shown in (Fig. 2).

\section{UV Visible spectroscopy}

Gold nanoparticles (AuNPs) of Punica granatum peel extract was exposed to UVVisible Spectrophotometer and showed a specific surface plasma resonance with a characteristic peak in visible spectrum at $525 \mathrm{~nm}$ reveals the fabrication of AuNPs as shown in (Fig. 3). This suggests that the phytochemicals found in the plants extracts act as both stabilizing and reducing agent.

\section{Phytochemical analysis of $P$. granatum} peel extract

Crude extract and fractions of $P$. granatum peel extract were evaluated for the presence of different phytochemical constituents. The results indicated the occurrence $(+)$ or absence (-) of various compounds in each extract as shown in (Table 1). 


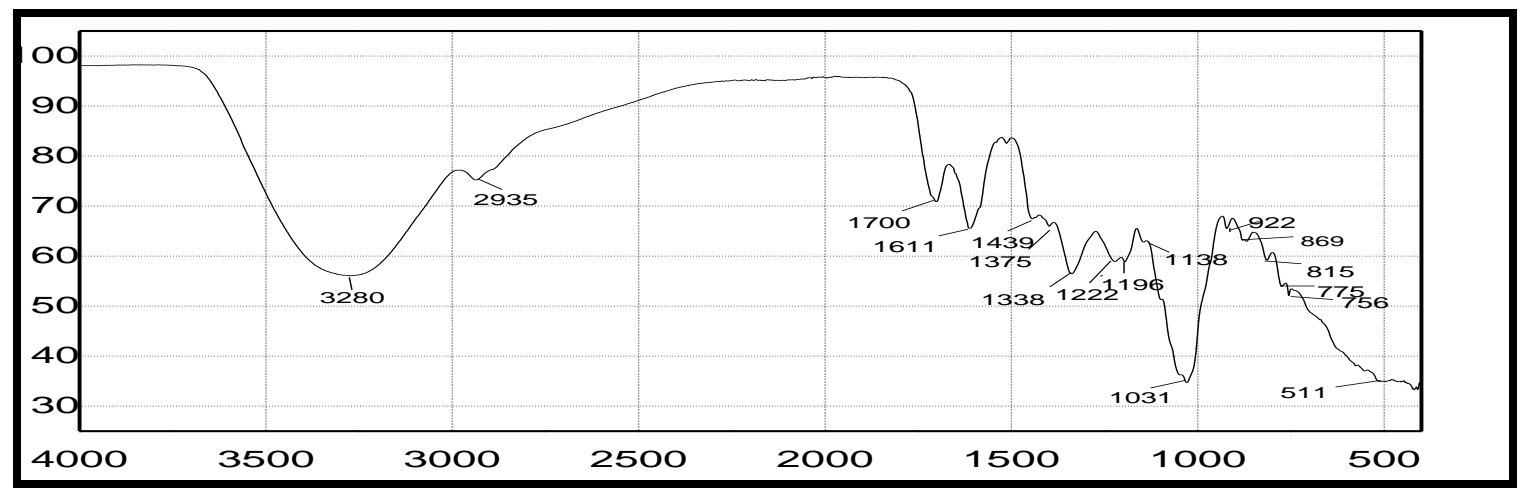

Figure 1. FTIR analysis of $P$. granatum peel aqueous extract

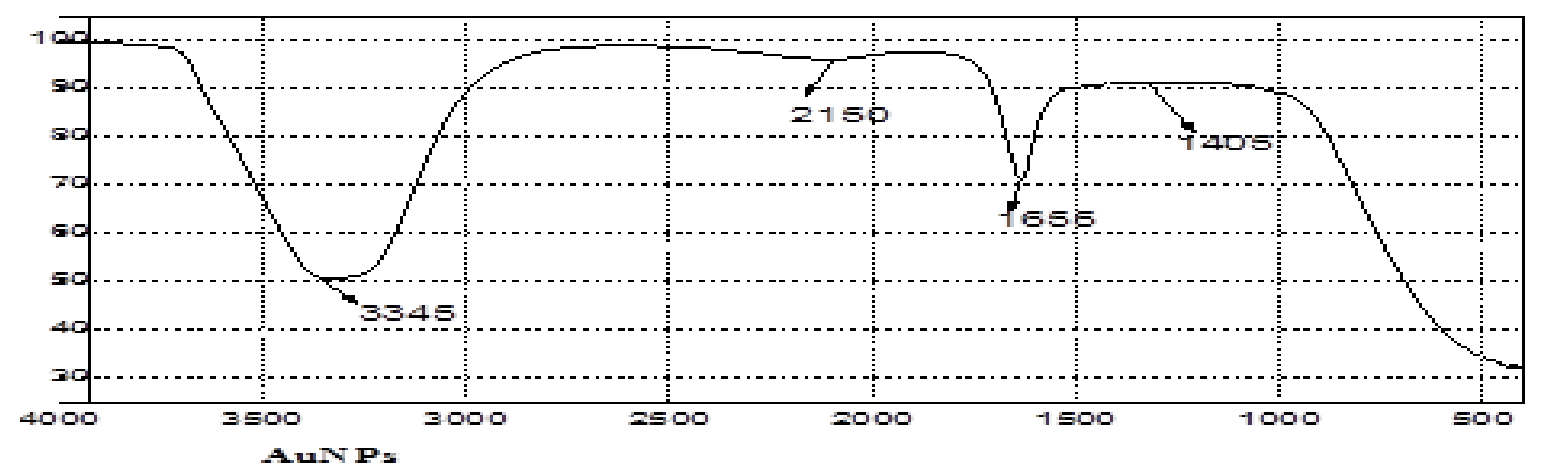

Figure 2. FTIR analysis of synthesized gold nanoparticles of $P$. granatum

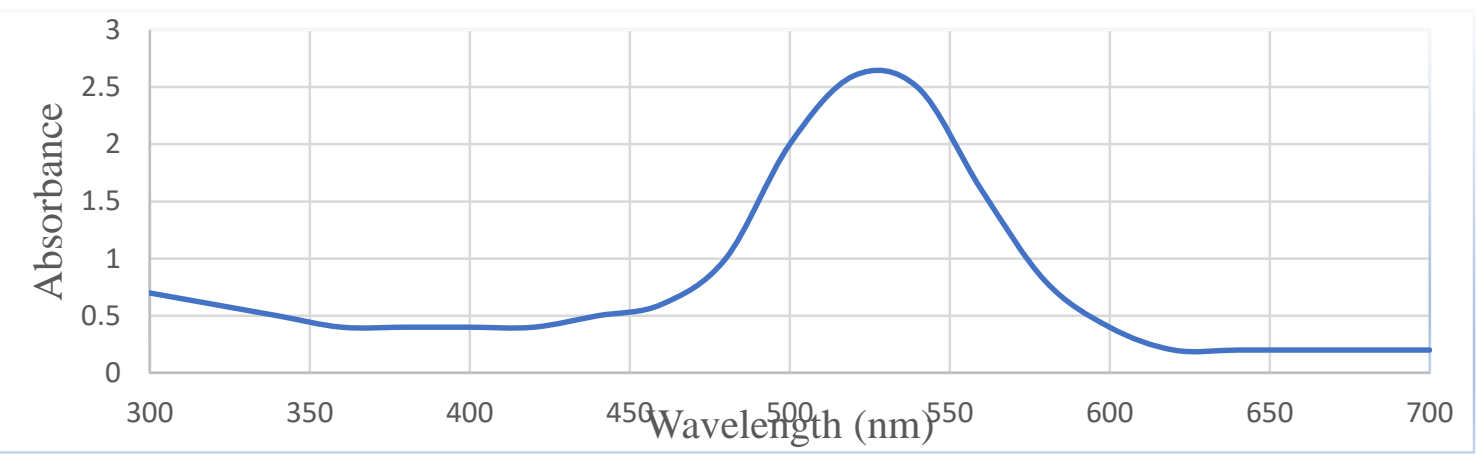

Figure 3. UV Visible spectroscopy of gold nanoparticles of $\boldsymbol{P}$. granatum

Table 1. Phytochemical analysis of $P$. granatum peel extract

\begin{tabular}{|c|c|c|c|c|c|c|}
\hline S. No. & Phytochemicals & Aqueous & Methanolic & Chloroform & Ethyl acetate & Butanol \\
\hline 1 & Tannins & + & + & + & + & + \\
\hline 2 & Steroids & + & + & + & + & + \\
\hline 3 & Glycosides & + & + & + & + & + \\
\hline 4 & Quinones & - & - & - & - & - \\
\hline 5 & Saponins & + & + & + & + & + \\
\hline 6 & Alkaloids & + & + & + & + & + \\
\hline 7 & Flavonoids & + & + & + & + & + \\
\hline
\end{tabular}

$+=$ Presence of phytochemicals, $-=$ Absence of phytochemicals 
Antibacterial activity of $P$. granatum crude extracts and fractions

$1 \mathrm{~g}$ peel extract dissolved in $10 \mathrm{ml}$ DMSO. Three different concentrations, i.e. (50, 75, $100 \mu \mathrm{l})$ were used. DMSO and Gentamicin was used as negative and positive control respectively. These Plants have strong biomedical and phytomedicine Ingredients. Punica. granatum have a lot of therapeutic uses against different disorders [3]. Resistance of antibiotics to disease causing microbes forced researchers to find out new ways for the treatment of microbial disorders such as using medicinal plants. This works revealed the potential of $P$. granatum as drug sources [15].

Keeping in mind the above facts $P$. granatum peel extract were used against different pathogenic bacteria. The result revealed that the peel extract have significant activity against all the bacterial species. $P$. granatum peel extract are concentration dependent. Lowest activity showed at $50 \mu 1$ against $E$. coli $(33.33 \%)$. While highest activity showed by aqueous extract $(91.66 \%)$ against $P$. aeroginosa. The whole summary are given below in (Fig. 4).

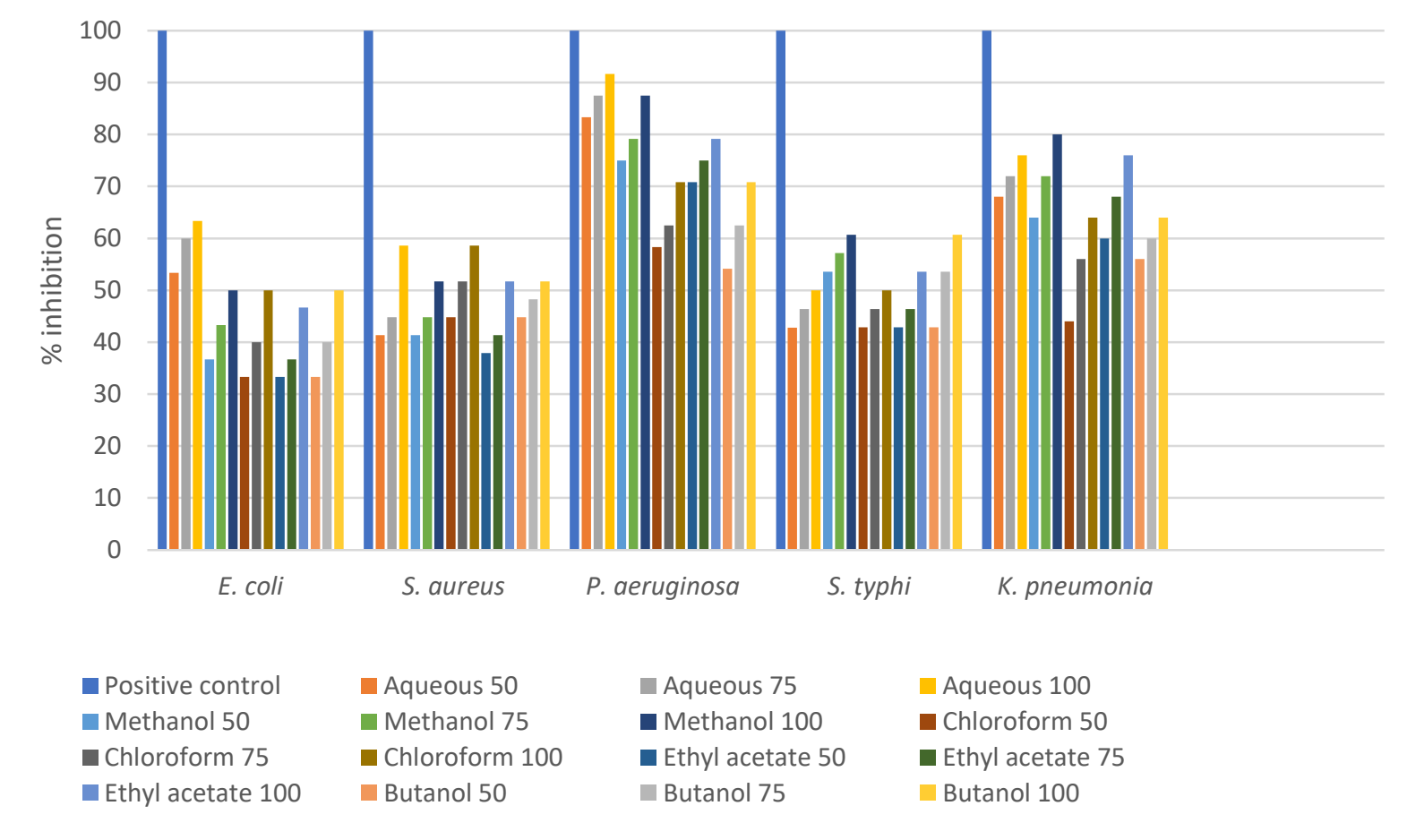

Figure 4. Antibacterial activity of $\boldsymbol{P}$. granatum peel crude extract

Antifungal activity of $P$. granatum peel extract

Fungal diseases always caused by pathogenic fungi to both plants and animals, which interrupts the physiological activities, structure and economic value. For the treatments of fungal diseases fungicides are used but some time they have adverse effect on humans, plants and environment. By the use of pharmaceutical drugs the pathogens some time show resistance. Drug resistance to disease causing microbes forced researchers to find out new ways for the treatment of microbial disorders such as using of medicinal plants. Punica. granatum 
peel crude extract have strong antifungal activity against disease causing fungi [25].
Antifungal activity increased with increasing

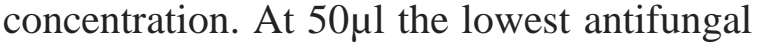

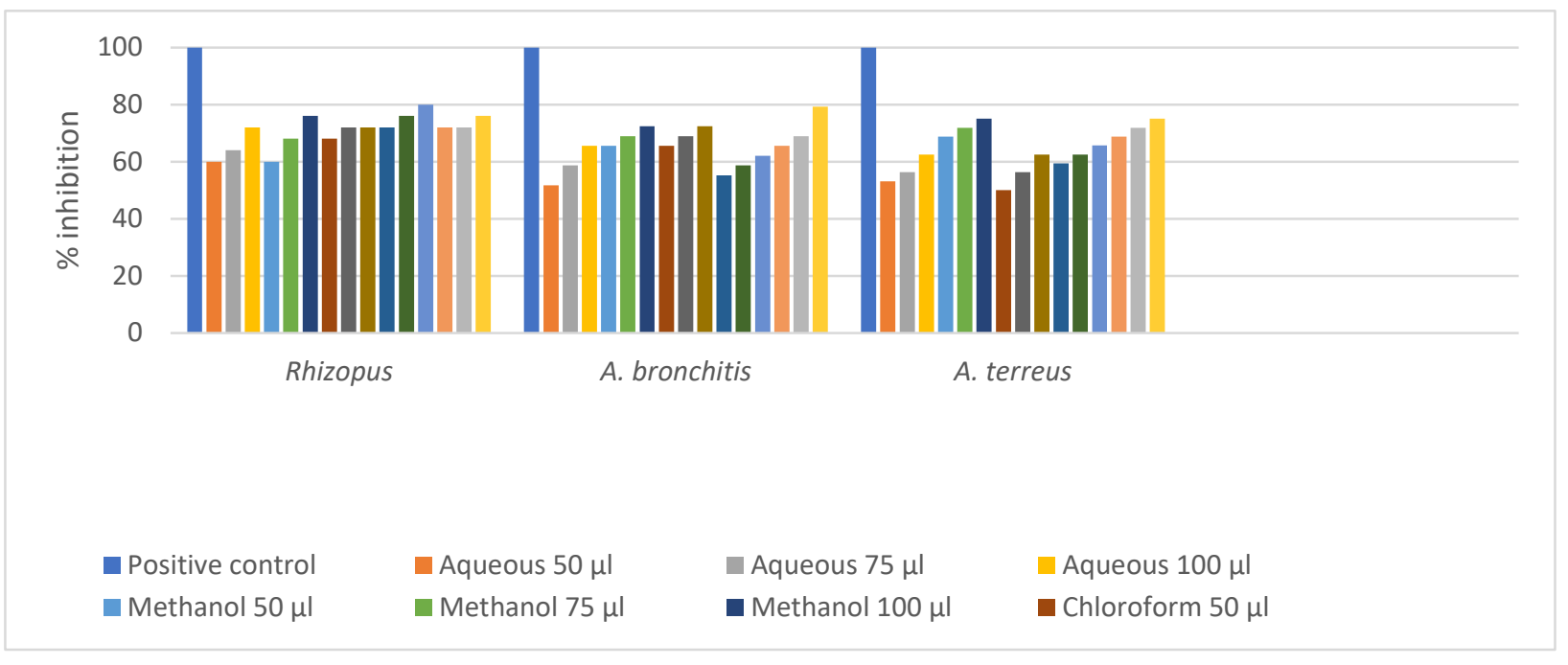

Keeping the above facts in mind the $P$. granatum peel crude extracts and fractions have screened against pathogenic fungi. The result showed that the test samples have significant activity against all tested microorganisms, as given below. activity showed by chloroform fraction was (50\%) against $A$. terreus. Antifungal activity ranges between $50 \%$ up to $76 \%$. Highest zone of inhibition showed by methanol extract (76\%) against Rhizopus. whole summery of the result are given in (Fig. 5).

\section{Figure 5. Antifungal activity of $P$. granatum peel crude extract}

\section{Antibacterial activity of extract mediated AuNPs}

Nanoparticles are extremely small particles (one billionth part of the meter $10^{-9}$ ). The preparation of NPs by chemical method are harmful and may affect human health and environment. The biological method for synthesis of NPs are ecofriendly, cheap and reliable. The application of NPs are increasing rapidly due to its potential antimicrobial activities [17].

Keeping the above facts in mind the extract mediated AuNPs of Punica granatum are screened against different bacterial species. A summary of the results are summarized in (Fig. 6). At $50 \mu 1$ the antibacterial activity of AuNPs showed $(51.72 \%)$ against $S$. aureus. At $75 \mu 1$ lowest activity was $(55.17 \%)$ against
S. aureus while highest activity was $(87.5 \%)$ against $P$. aeroginosa. At $100 \mu 1$ lowest activity was $(62.06 \%)$ against $S$. aureus, while highest activity was $(91.66 \%)$ against P. aeroginosa (Fig. 6).

Extract mediated AuNPs of $P$. granatum peel extract are concentration dependent. Antifungal activity increased with increasing concentration of NPs. AuNPs have significant role in microbiology due to its strong antimicrobial property. In present study extract mediated AuNPs have low to significant activities against fungus species. The lowest activity showed (58.62\%) against A. bronchitis at $50 \mu 1$. while highest activity

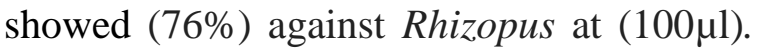
The moderate activity showed at $75 \mu \mathrm{l}$ ranges from $(65.62 \%)$ to $(72 \%)$ (Fig. 7$)$. 


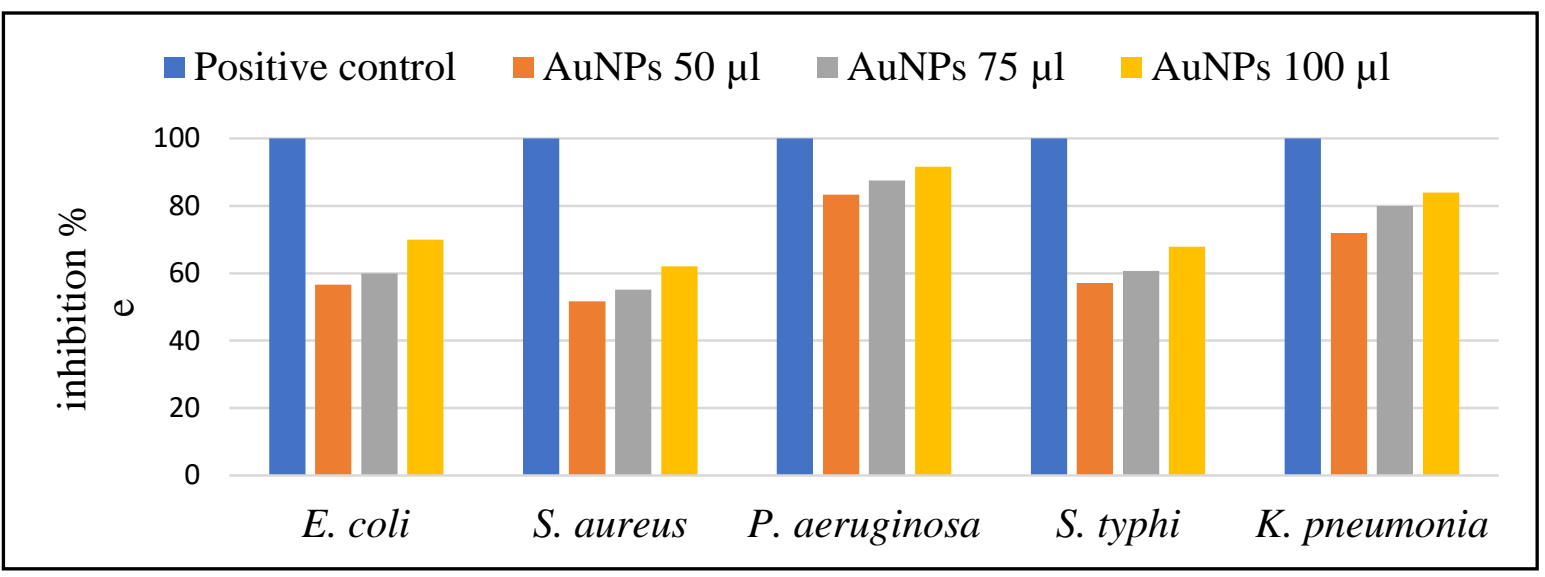

Figure 6. Antibacterial activity of plant mediated AuNPs (50, 75, $100 \mu \mathrm{l})$

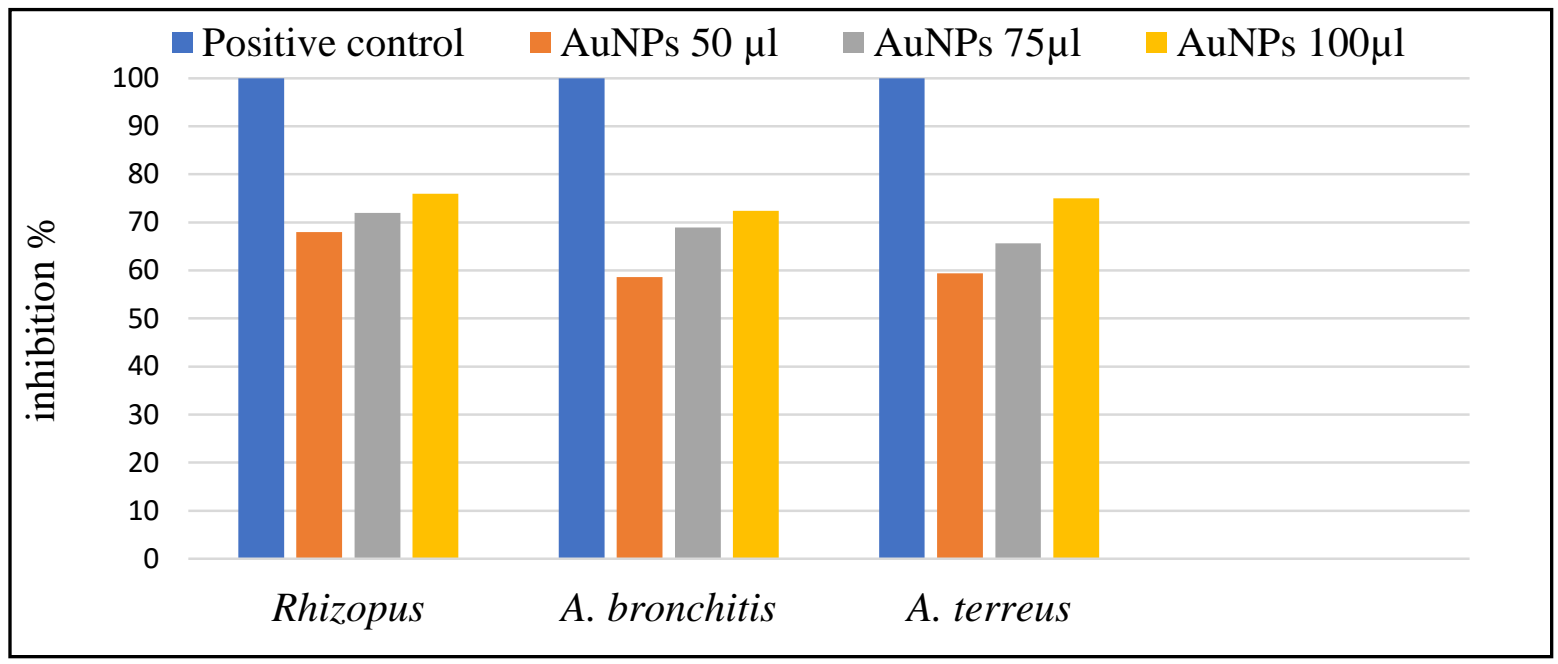

Figure 7. Antifungal activity of plant mediated AuNPs $(50,75,100 \mu \mathrm{l})$

Free radical scavenging activity

Antioxidants are the ingredients that inhibit oxidation which are capable to remove harmful oxidizing substances existing in the body of physiological organisms. Medicinal plants have the potential to completely treat or reduce oxidative damage to body tissue which may cause cancer or other deadly diseases. So it's highly suggested to investigate different ingredients in therapeutic plants. Natural sources like vegetables, fruits and whole grains have ingredients which inhibit oxidative damage through free radicals and cause metabolic and cellular injuries, accelerating aging, heart diseases, cancer, neurodegenerative and inflammation diseases [26].

Phenolic acids and carotenes, vitamin $\mathrm{C}$ and $\mathrm{E}$ are Phyto antioxidants which have the capability to decrease the risk of diseases. Free radical, 2, 2-Diphenyl-1-picrylhydrazyl (DPPH) is cheap reliable and easy technique to measure antioxidant capability of plant. These technique is commonly used to measure the capability of compound for free radical scavenger and hence to estimate antioxidant activity, [27]. The result achieved from the present result displayed in (Fig. 8), which showed that by increasing the concentration of the sample the percent inhibition also increased. 


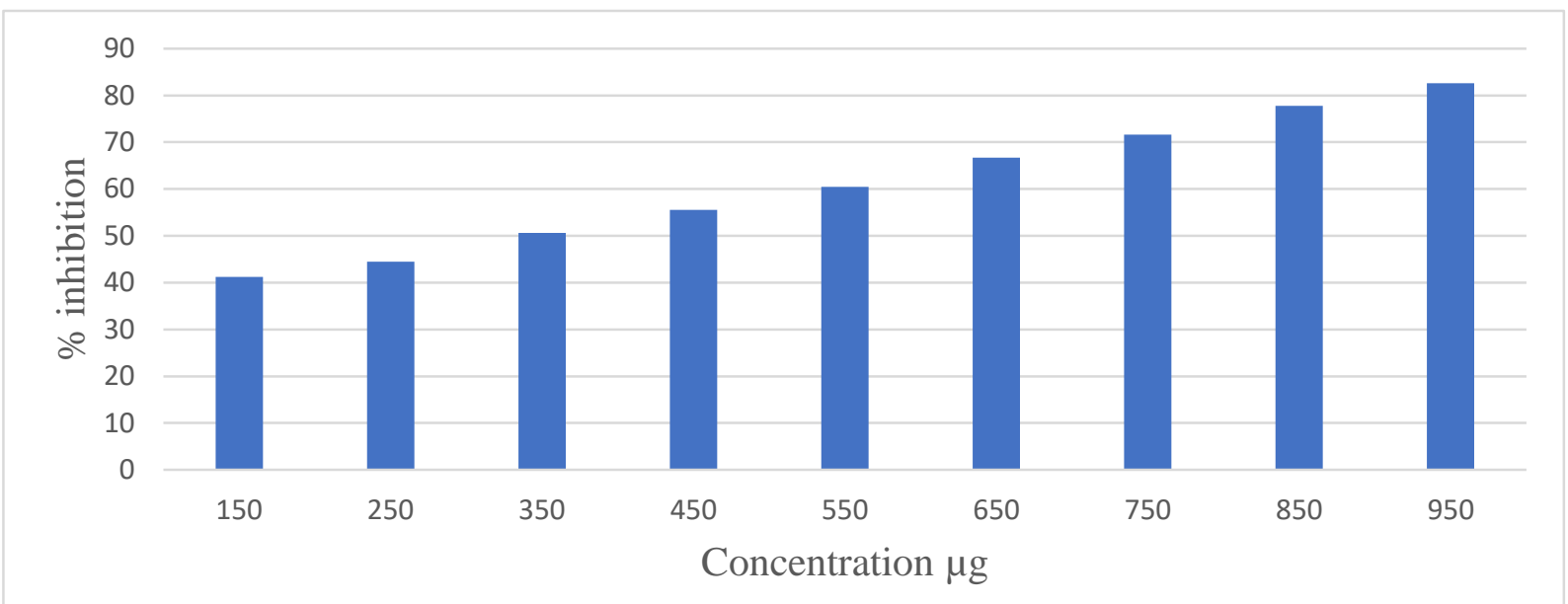

Figure 8. Antioxidant activity of $P$. granatum peel extract

\section{Discussion}

Present study was carried out to determine the effect of plant extract and gold nanoparticles (AuNPs) against pathogenic microorganisms. Pathogenic bacteria and fungi were used in present study. Two types of extract and three fractions were prepared. Standard operating procedures (SOP) was followed during whole research work.

Singh et al. [28] conducted his research work on phytochemical screening to find out different secondary metabolites in Punica granatum. His study revealed that different chemical compounds are present in $P$. granatum peel. According to our research work steroids, saponins, tannins, glycosides, flavonoids and alkaloids are present but quinones are not present in extracts and fractions. Previous research works have close correlation with our results.

Kumar et al. [17] stated that when gold salt solution was mixed with $P$. granatum extract the color changed to dark ruby pink red which is sign of confirmation of AuNPs. $P$. granatum AuNPs show surface plasmon resonance peaks of $580 \mathrm{~nm}$. While in present study AuNPs of $P$. granatum peel surface plasma resonance with a characteristic peak in visible spectrum at $525 \mathrm{~nm}$. The changing of color to dark ruby pink red indicate the process of formation of AuNPs.
Yadav et al. [29] stated that NPs have strong antifungal and antibacterial activity on different concentration. Different pathogenic microorganisms were tested. In previous study zone of inhibition ranges from 7 to 21 $\mathrm{mm}$, while in present study same concentration of NPs were used and zone of inhibition were found increased with increasing concentration. The lowest zone were showed on $50 \mu \mathrm{L}$ of $15 \mathrm{~mm}(51.72 \%)$ against $S$. aureus while the highest zone showed on $100 \mu \mathrm{L}$ of $22 \mathrm{~mm}(91 \%)$ against $P$. aeruginosa. Same concentration of NPs also used against fungus species ranges from 17 to $24 \mathrm{~mm}$. The lowest zone were showed on $50 \mu \mathrm{L}$ of $17 \mathrm{~mm}(58 \%)$ against $A$. bronchitis while highest zone were recorded on $100 \mu \mathrm{L}$ of $24 \mathrm{~mm}(75 \%)$ against $A$. terreus.

Nweze et al. [20] carried out the antibacterial activity of $P$. granatum peel extract and fractions against different bacterial species. In present study different zones of inhibitions was observed which increased with increasing concentration. Lowest activity showed by EtOAc fraction of $10 \mathrm{~mm}$ $(33.33 \%)$ against E.coli. While best activity showed by aqueous extract of $22 \mathrm{~mm}$ $(91.66 \%)$ against $P$. aeruginosa. Iqbal's study has close correlation with our research work. 
Rangasamy et al. [25] stated that antifungal activity increased with increasing concentration of NPs. Strong antifungal activity depend on the presence of secondary metabolites in $P$. granatum crude extract. In present study peel extract have low to significant activities against fungus species. At $50 \mu \mathrm{l}$ lowest activity showed by ethyl acetate fraction of $16 \mathrm{~mm}(55 \%)$ against $A$. bronchitis. While best activity showed by methanol extract of $24 \mathrm{~mm}(75 \%)$ against $A$. terreus. Activity of crude extract increased with increasing concentration. The Oraki research work have strong correlation with our research work.

Sakagami et al. [30] stated that the FTIR of $P$. granatum showed different peaks. Each peak indicates the presence of organic compounds. In the present study FTIR of peel extract and extract mediated AuNPs, was carried out in the range of $400-400 \mathrm{~nm}$ in case of crude extract while 300-700 nm used for AuNPs. Different peaks were detected which indicates the presence of different secondary metabolites.

From the above results its reveal that $P$. granatum have significant potential and can be useful to prepare new products for pharmacological study, food preservatives, natural antioxidant and synthesis of effective drugs for the treatment of different diseases.

\section{Conclusion and Recommendation}

Punica granatum peel have strong antimicrobial activity so it's recommended to further evaluate the activity of $P$. granatum against different pathogens. Gold nanoparticles have strong antimicrobial activities it is suggested for the future researchers to use different metals for the synthesis of NPs e.g. (copper, iron, silver and zinc). Different peaks were observed in FTIR result which indicates the presence of organic compounds. Continuously research work is required on pathogenic microorganisms to find out current status and resistance toward different antibiotics. Keeping in mind the above facts we concluded that different ingredients are present in these extract which can be used for pharmacological study, food preservatives, natural antioxidant and medicinal purposes.

Authors' contributions

Conceived and designed the experiments: FU Samad, M Rizwan, K Bashir, Muhammad, A Rauf \& NU Samad, Performed the experiments: FU Samad, NU Samad \& MA Ahmad, Analyzed the data: FU Samad \& K Bashir, Contributed reagents/ materials/ analysis tools: S Jafer, B khan, A Malik \& MA Ahmad, Wrote the paper: FU Samad \& NU Samad.

\section{References}

1. Ahmad N, Sharma S \& Rai R (2012). Rapid green synthesis of silver and gold nanoparticles using peels of Punica granatum. Adv Mater Lett 3(5): 376380.

2. Akter SA, Sarker and Hossain MD (2013). Antidiarrhoeal activity of rind of Punica granatum. Int Curr Pharm 2(5): 101-104.

3. Annamalai A, Babu ST, Jose NA, Sudha D \& Lyza CV (2011). Biosynthesis and characterization of silver and gold nanoparticles using aqueous leaf extraction of Phyllanthus amarus Schum \& Thonn. World Appl Sci J 13(8): 1833-1840.

4. Belkacem N, Djaziri R, Lahfa F, El-Haci IA \& Boucherit Z (2014). Phytochemical screening and in vitro antioxidant activity of various Punica granatum 1 . Peel extracts from Algeria: A comparative study. Phytothérapie 12(6): 372-379.

5. Bhandary SK, Bhat VS, Sharmila KP \& Bekal MP (2012). Preliminary phytochemical screening of various extracts of Punica granatum peel, whole fruit and seeds. J Health Allied Sci 2(04): 34-38. 
6. Çam M \& Hiş1l Y (2010). Pressurised water extraction of polyphenols from pomegranate peels. Food Chem 123(3): 878-885.

7. Devanesan S, AlSalhi MS, Balaji RV, Ranjitsingh AJA, Ahamed A, Alfuraydi AA \& Othman AH (2018). Antimicrobial and cytotoxicity effects of synthesized silver nanoparticles from Punica granatum peel extract. Nanoscale Res Lett 13(1): 315-318.

8. Farag R, Abdel-Latif MS, Emam SS \& Tawfeek LS (2014). Phytochemical screening and polyphenol constituents of pomegranate peels and leave juices. Agr Soil Sci 1(6): 86-93.

9. Ganeshkumar M, Sathishkumar M, Ponrasu T, Dinesh MG \& Suguna L (2013). Spontaneous ultra fast synthesis of gold nanoparticles using Punica granatum for cancer targeted drug delivery. Colloids Surf B 106: 208-216.

10. Garachh D, Patel A, Chakraborty M and Kamath JV (2012). Phytochemical and pharmacological profile of Punica Granatum: An overview. Int Res J Pharm 3(2):65-68.

11. Hajleh MA \& Al-Dujaili ASE (2016). Anti-cancer activity of pomegranate and its biophenols; general review. $E C$ Nutrition 6(1): 28-52.

12. Heiligtag FJ \& Niederberger M (2013). The fascinating world of nanoparticle research. Materials Today 16(7-8): 262271.

13. Iqbal S, Arifeen S, Akbar A, Zahoor S, Maher S, Khan N \& Sajjad A (2019). 76. Phytochemical screening and antibacterial assay of the crude extract and fractions of Ferula oopoda. Pure Appl Biol 8(1): 742-749.

14. Iravani S (2011). Green synthesis of metal nanoparticles using plants. Green Chem 13(10): 2638-2650.

15. Jayaprakash A \& Sangeetha R (2015). Phytochemical screening of Punica granatum Linn. peel extracts. $J$ of acad and ind res 4(5): 160-162.

16. Kadi H, Nahal BN, Benyahia A, Meddah B \& Moussaoui A (2015). Phytochemical and antibacterial screening of Punica granatum L. bark of South-west Algeria.J chem pharm res 7(8): 880-884.

17. Kumar A, Ilavarasan R, Jayachandran T, Decaraman M, Aravindhan PN, Padmanabhan and Krishnan MRV (2009). Phytochemicals Investigation on a Tropical Plant, Syzygium cumini from Kattuppalayam, Erode District, Tamil Nadu, South India. Pak J Nutr 8(1): 8385.

18. Kumar M, Dandapat S \& Sinha MP (2015). Phytochemical screening and antibacterial activity of aqueous leaf extract of Punica granatum. Balneo Res $J$ 6(3): 168-171.

19. Mohammad G, Al-Jassani MJ \& Hameed IH (2016). Anti-bacterial, Antifungal Activity and Chemical Analysis of Punica grantanum (Pomegranate peel) Using GC-MS and FTIR Spectroscopy 8(3): 480-494

20. Nweze CC, Abdulganiyu $\mathrm{MG}$ and Erhabor OG (2015). Comparative analysis of vitamin-C in fresh fruit juice of Malus domestica, Citrus sinensi, Ananas comosus and Citrullus lantus by Iodometric Titration. Int J Sci Environ Technol 4(1):17-22.

21. Oraki HH, Demirci AŞ \& Gümüş $T$ (2011). Antibacterial and antifungal activity of pomegranate (Punica granatum L. cv.) peel. Elec J Env Agricult Food Chem 10(3).

22. Parekh J \& Chanda S (2007). Antibacterial and phytochemical studies on twelve species of Indian medicinal plants. AFR J BIOMED RES 10(2).

23. Prakash CVS and Prakash I (2011). Bioactive chemical constituents from pomegranate (Punica granatum) juice, 
seed and peel-a review. Int J Res Chem Environ 1(1): 1-18.

24. Qnais EY, Elokda AS, Ghalyun YYA and Abdulla FA (2007). Antidiarrheal activity of the aqueous extract of Punica granatum (Pomegranate) Peels. Pharm Biol 45(9): 715-720.

25. Rangasamy $K$ and Namasivayam $E$ (2014). In vitro Antioxidant and Free Radical Scavenging Activity of Isolongifolene. Asian J Biol Sci 7(1): 1323

26. Ricci D, Giamperi L, Bucchini A \& Fraternale D (2006). Antioxidant activity of Punica granatum fruits. Fitoterapia 77(4): 310-312.

27. Santos ÉS, Hoscheid J \& Mata PTG (2015). Antibacterial activity of crude ethanolic and fractionated extracts of
Punica granatum Linn. fruit peels. J Appl Pharm Sci 36(2).

28. Singh RP, Chidambara MKN \& Jayaprakasha GK (2002). Studies on the antioxidant activity of pomegranate (Punica granatum) peel and seed extracts using in vitro models. J Agric Food Chem 50(1): 81-86.

29. Yadav M, Chatterji S, Gupta SK and Watal G (2014). Preliminary phytochemical screening of six medicinal plants used in traditional medicine. Int J Pharm Pharm Sci 6(5): 539-542.

30. Sakagami Y, Murata H, Nakanishi T, Inatomi Y, Watabe $\mathrm{K}$, Iinuma $\mathrm{M} \&$ Lang FA (2001). Inhibitory effect of plant extracts on production of verotoxin by enterohemorrhagic Escherichia coli O157: H7. J Health Sci 47(5): 473-477. 